
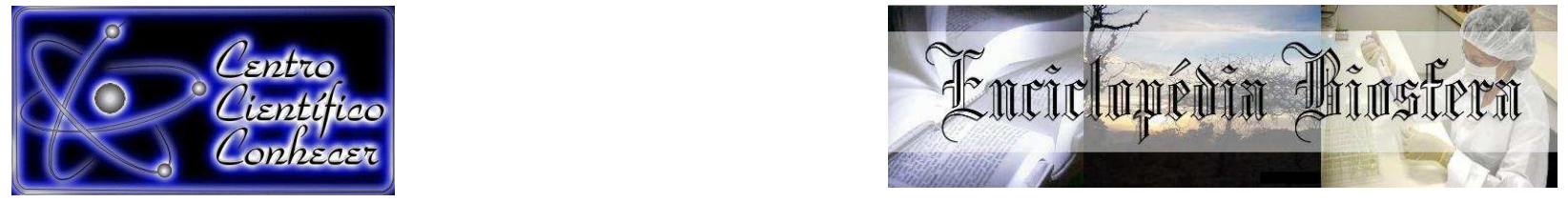

\title{
DESEMPENHO AGRONÔMICO DE GENÓTIPOS DE GIRASSOL NO SUDOESTE BAIANO PARA PRODUÇÃO DE BIOCOMBUSTÍVEIS
}

Marcelo Silva Santana ${ }^{1}$, Vandearley Neves de Souza ${ }^{1}$, Gisella Martha Silva Simões dos Santos ${ }^{1}$, Leandro Gonçalves dos Santos ${ }^{2}$, Leandro Santos Peixouto ${ }^{2}$

${ }^{1}$ Graduando em Agronomia, Instituto Federal de Educação, Ciência e Tecnologia Baiano, (marcelosantana-iga@hotmail.com), Guanambi, Bahia

${ }^{2}$ Professor Doutor, Instituto Federal de Educação, Ciência e Tecnologia Baiano Campus Guanambi

Recebido em: 08/04/2016 - Aprovado em: 30/05/2016 - Publicado em: 20/06/2016 DOI: 10.18677/Enciclopedia_Biosfera_2016_037

\begin{abstract}
RESUMO
O girassol é uma planta extremamente adaptável, podendo ser cultivada sob amplo espectro de condições ambientais e por apresentar baixa sensibilidade ao fotoperíodo, desenvolve-se em várias latitudes e ambientes, fazendo com que o manejo mais adequado para obtenção de máximas produções sofra variações dentro de um mesmo país. O experimento foi conduzido em condições de campo em área experimental do Instituto Federal de Educação, Ciência e Tecnologia Baiano, Campus Guanambi, com objetivo desse trabalho foi avaliar o comportamento produtivo de grãos e produção de óleo de diferentes cultivares de girassol nas condições edafoclimáticas da região Sudoeste da Bahia. $O$ delineamento experimental foi em blocos completos casualizados com quatro repetições. Os tratamentos constaram da avaliação competitiva de 16 genótipos de girassol: BRS G30, BRS G34, BRS G35, BRS G36, BRS G37, BRS G38, BRS G39, BRS G40, BRS G41, BRS G42, Embrapa 122, M734, MG341, HELIO 358, SYN 3950 HO e MG 305. Avaliaram-se as características: stand de plantas, altura de plantas, floração inicial, tamanho do capítulo, produtividade de grãos, peso de mil aquênios, teor de óleo no grão e rendimento de óleo. O genótipo de estatura mais elevada, BRS G36, demonstrou ser o genótipo menos precoce. Os genótipos MG341 e BRS G41 foram os de maior produtividade de grãos, contudo o maior rendimento de óleo foi obtido no genótipo BRS G41.
\end{abstract}

PALAVRAS-CHAVE: biodiesel, Helianthus annuus, oleaginosa.

\section{PERFORMANCE SUNFLOWER GENOTYPES AGRICULTURE IN SOUTHWEST BAHIA FOR BIOFUELS PRODUCTION}

\begin{abstract}
Sunflower is an extremely adaptable plant. It can be grown under broad spectrum of environmental conditions and, because of its low sensitivity to photoperiod, is developed at many different latitudes and environments, making the most suitable management for achieving maximum yields suffer variations within the same country. The experiment was conducted under field conditions in the experimental area of the
\end{abstract}


Instituto Federal de Educação, Ciência e Tecnologia Baiano, Campus Guanambi. The objetive of this study was to evaluate the productive behavior of grain and oil production of different cultivars of sunflower in the soil and climatic conditions of the southwest of Bahia region. The experimental design was a randomized complete block design with four replications. The treatments were competitive evaluation of 16 sunflower genotypes: BRS G30, BRS G34, BRS G35, BRS G36, BRS G37, BRS G38, BRS G39, BRS G40, BRS G41, BRS G42, Embrapa 122, M734, MG341, HELIO 358, SYN $3950 \mathrm{HO}$ and MG 305. The characteristics evaluated were: plant stand, plant height, early flowering, capitulum length, grain yield, weight of a thousand achenes, oil content in grain and oil yield. The highest height of genotype, BRS G36, proved to be the least precocious. The MG 341 and BRS G41 genotypes had the highest grain yield, however the highest oil yield was obtained in BRS G41 genotype.

KEYWORDS: biodiesel, Helianthus annuus, oleaginous.

\section{INTRODUÇÃO}

O girassol (Helianthus annuus L.) é uma das poucas culturas com um amplo espectro de adaptação às diversas condições de latitude, longitude e fotoperíodo. Sua tolerância à seca, ao frio e ao calor, bem como sua independência de maquinário especializado, caracterizam seu cultivo como rústico e econômico (CAVASIN JUNIOR, 2001).

Trata-se de uma cultura anual que, do ponto de vista econômico, apresenta grande viabilidade no Nordeste. A adaptabilidade, o aproveitamento de suas sementes e de sua massa seca, o teor de óleo em torno de $40 \%$, aliado com a sua crescente valorização no mercado, são o cenário ideal para a geração de retornos financeiros (FREITAS, 2012). Mesmo assim, a cultura ainda enfrenta alguns desafios no país, como a possibilidade de cultivares que permitam uma segunda colheita, matéria-prima oleaginosa e óleo comestível de alto valor nutritivo. Junta-se a esses desafios a alternativa atual da produção de energia, já que o óleo de girassol pode ser utilizado como matéria-prima para a produção de biocombustíveis (TORDIN, 2008).

O Brasil ainda é considerado como um pequeno produtor de girassol, com uma área cultivada em torno de 139,9 mil hectares para safra 2013/14. O Nordeste brasileiro, nos últimos anos, aparece como região produtora, contribuindo com $0,4 \%$ do total plantado no país, sendo a região de destaque o Centro-Oeste que contribui com $89,7 \%$ de área plantada e $90,3 \%$ da produção nacional (CONAB, 2014).

A escassez de estudos sobre avaliação competitiva de genótipos nas diferentes localidades, visando o ganho na produtividade ainda é um entrave para a expansão da cultura do girassol no Brasil. Para OLIVEIRA et al. (2010), além de incrementar a produtividade, o uso de cultivares de melhor adaptação constitui-se em insumo de baixo custo no sistema de produção e, consequentemente, de fácil adoção pelos produtores.

O cultivo de girassol vem se apresentando como opção de rotação e sucessão de culturas nas regiões produtoras de grãos. Sua melhor tolerância à seca, baixa incidência de pragas e doenças, além dos benefícios proporcionados às culturas subsequentes e ao solo, são alguns dos fatores que vêm ampliando o cultivo dessa oleaginosa em diversas regiões brasileiras (GAZZOLA et al., 2012). Com isso o conhecimento de cultivares adaptadas as condições de plantio se torna 
fundamental para difusão da cultura e obtenção de melhores índices de produção de grãos.

Diante do potencial da espécie, tanto na utilização de óleos como de subprodutos para alimentação humana e animal, bom como de sua importância dentro do sistema produtivo, objetivou-se avaliar diferentes genótipos de girassol $(H$. annuus L.) no Sudoeste Baiano visando à produção de biocombustíveis.

\section{MATERIAL E MÉTODOS}

O experimento foi conduzido em condições de campo no município de

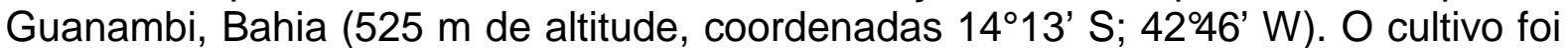
conduzido no período de maio a setembro, sem ocorrência de precipitação e conforme as condições de temperatura e umidade do ar presentes na Figura 1.

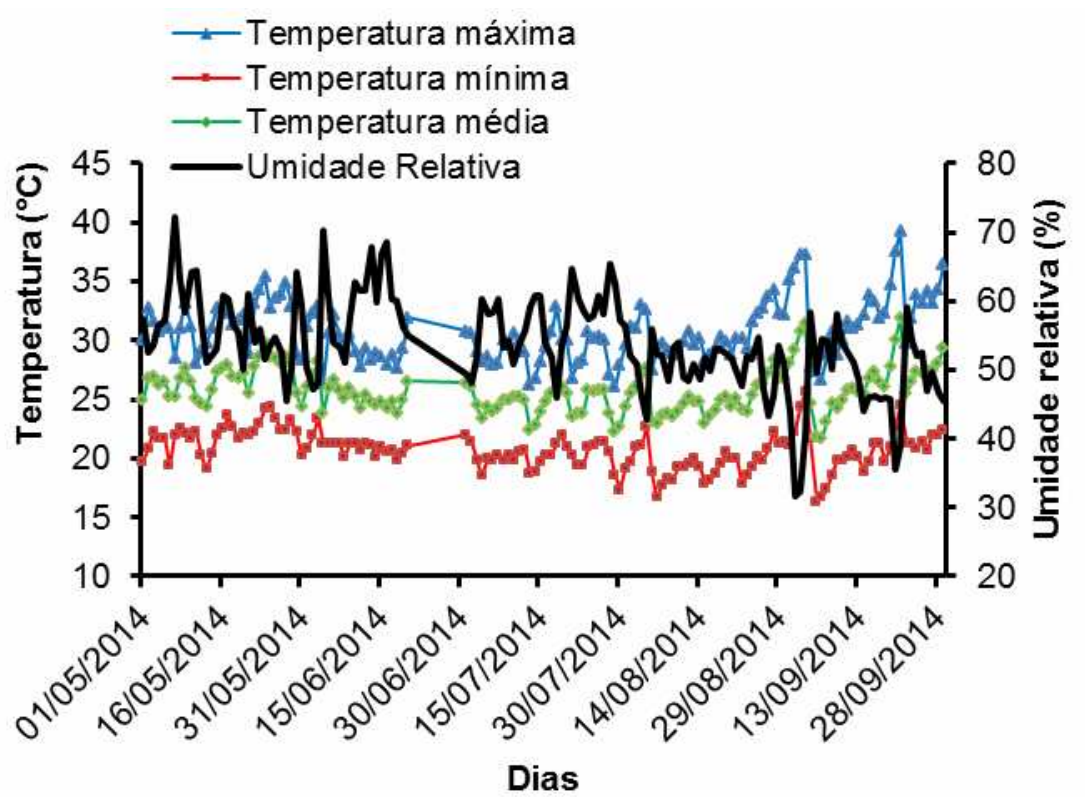

FIGURA 1. Temperatura e umidade relativa do ar observada durante o período de avaliação.

O delineamento experimental foi em blocos, sendo 16 tratamentos e oito repetições. O bloco possuía dimensões equivalentes a $6 \mathrm{~m} \times 22,4 \mathrm{~m}$ contendo 8 parcelas de $6 \mathrm{~m} \times 2,80 \mathrm{~m}$ em cada bloco. Foram utilizados 16 genótipos (BRS G30, BRS G34, BRS G35, BRS G36, BRS G37, BRS G38, BRS G39, BRS G40, BRS G41, BRS G42, Embrapa 122, M734, MG341, HELIO 358, SYN 3950 HO e MG 305), disponibilizados pela Rede Nacional de Ensaios de Girassol que é gerenciada pela Embrapa Soja. Cada parcela experimental foi composta por quatro linhas com 6 $\mathrm{m}$ de comprimento cada, no espaçamento de $0,7 \mathrm{~m} \times 0,3 \mathrm{~m}$.

Antes da semeadura, realizou-se adubação de fundação de maneira a garantir o suprimento de $40 \mathrm{~kg} \mathrm{~N}^{-1}$ (Ureia), $80 \mathrm{~kg} \mathrm{P}_{2} \mathrm{O}_{5} \mathrm{ha}^{-1}$ (Super Fosfato Simples) e $40 \mathrm{~kg} \mathrm{~K}_{2} \mathrm{O} \mathrm{ha}^{-1}$ (Cloreto de Potássio), com base na análise de solo que apresentou as seguintes características: $(0-30 \mathrm{~cm})$ podem ser descritas por: $\mathrm{pH}$ $(\mathrm{H} 2 \mathrm{O})=7,3 ; \mathrm{Ca}^{2+}+\mathrm{Mg}^{2+}=5,4 \mathrm{cmol}_{\mathrm{c}} \mathrm{dm}^{-3} ; \mathrm{Ca}^{2+}=3,7 \mathrm{cmol}_{\mathrm{c}} \mathrm{dm}^{-3} ; \mathrm{K}=0,82 \mathrm{cmol}_{\mathrm{c}} \mathrm{dm}^{-3}$ (Mehlich-1); $\mathrm{P}=135 \mathrm{mg} \mathrm{dm}^{-3}$ (Mehlich-1); CTC $=6,3 ; \mathrm{V}=85 \%$ e PST $=1 \%$. Aos vinte e cinco dias após a emergência das plantas, realizou-se a adubação de cobertura com $40 \mathrm{~kg} \mathrm{~N} \mathrm{ha}^{-1}$ (Ureia), $40 \mathrm{~kg} \mathrm{~K}_{2} \mathrm{O} \mathrm{ha}{ }^{-1}$ (Cloreto de Potássio) e $2 \mathrm{~kg} \mathrm{~B} \mathrm{ha}^{-}$ 
${ }^{1}$ (Ácido Bórico), ao mesmo tempo em que também se realizou a capina com uso de enxadas.

Na semeadura foram colocadas três sementes por cova com espaçamento de $0,30 \mathrm{~m}$, visando à obtenção da densidade de 45000 plantas por hectare. $\mathrm{O}$ desbaste das plantas foi realizado aos sete dias após a emergência, deixando apenas uma planta por cova e vinte plantas por linha. O experimento foi conduzido sob regime de irrigação por gotejamento de maneira que o suprimento das necessidades hídricas em cada fase fenológica da cultura foi atendido conforme CASTRO \& FARIAS (2005) e levando-se em consideração as perdas por evapotranspiração no local.

Durante a condução do experimento não houve necessidade da aplicação de inseticidas ou fungicidas, tendo em vista a não ocorrência de insetos ou moléstias em níveis populacionais que colocasse em risco o desenvolvimento da cultura. A colheita estava prevista para ser realizada quando o teor de umidade nos grãos atingisse $11 \%$, contudo foi antecipada devido ao ataque de pássaros. Para evitar a proliferação de fungos devido ao teor de umidade ainda crítico, foi realizada a secagem dos capítulos em estufa a $65^{\circ} \mathrm{C}$ por $24 \mathrm{~h}$. De cada parcela foi desprezada a linha de bordadura de cada lado e uma planta das extremidades de cada linha.

Foram avaliadas as seguintes variáveis: stand de plantas, altura de plantas $(\mathrm{cm})$, floração Inicial (dias), diâmetro do capítulo, produtividade de grãos $\left(\mathrm{kg} \mathrm{ha}^{-1}\right)$, massa de mil aquênios $(\mathrm{g})$, teor de óleo no grão (\%) e rendimento de óleo $\left(\mathrm{kg} \mathrm{ha}^{-1}\right)$.

A floração inicial (FI) foi quantificada em dias após a emergência e determinada quando $50 \%$ das plantas da parcela estavam em estágio de floração. A altura da planta (AP) foi medida com auxílio de uma trena, medindo-se do nível do solo até a altura de inserção da haste no capítulo. O diâmetro do capítulo (DC) foi medido com auxílio de fita métrica, tendo por base a região mediana do capítulo. A produtividade de aquênios (PROD) foi resultante da quantificação de aquênios por planta na parcela útil. A massa de mil aquênios (MMA) foi obtida por meio da pesagem de 1000 aquênios obtidos de uma amostra composta de cada parcela. A umidade dos aquênios (UMI) foi determinada em estufa de secagem por meio por meio de uma amostra composta de cada parcela.

O teor de óleo foi obtido por meio da prensagem de uma amostra de grãos numa prensa hidráulica modelo TE-098 da Tecnal. Para isso pesou-se $300 \mathrm{~g}$ de grãos previamente aquecidos em estufa a $55^{\circ} \mathrm{C}$ por $3 \mathrm{~h}$ e extraíram-se o óleo com uma pressão de $495 \mathrm{kgf} \mathrm{cm}^{-2}(12 \mathrm{Mg}$ ) e o tempo de prensagem de $10 \mathrm{~min}$.

A significância do efeito dos tratamentos foi determinada por meio do Teste $F$, sendo as médias comparadas por meio do Teste de Scott-Knott $(p<0,05)$. Além da análise de variância foi realizado Análise de Correlação de Pearson.

\section{RESULTADOS E DISCUSSÃO}

$\mathrm{Na}$ avaliação inicial verificou-se que os genótipos HELIO 358, SYN $3950 \mathrm{HO}$ e MG 305 apresentaram stand insuficiente para prosseguimento das avaliações. Desta forma, o número de tratamentos foi reduzido para 13. Os genótipos que permaneceram em avaliação exibiram diferenças em relação as variáveis fenológicas e produtivas (Tabela 1). 
TABELA 1. Valores de "F", média e coeficiente de variação para stand de plantas (STD), data de floração inicial (DFI), diâmetro do capítulo (DC), altura de plantas $(A L T)$, produtividade de grãos (PROD), peso de mil aquênios (MMA), teor de óleo (TO) e rendimento de óleo (RO).

\begin{tabular}{lccccccccc}
\hline FV & GL & $\begin{array}{c}\text { STD } \\
\text { (plant) }\end{array}$ & $\begin{array}{c}\text { DFI } \\
(\text { dias })\end{array}$ & $\begin{array}{c}\text { DC } \\
(\mathrm{mm})\end{array}$ & $\begin{array}{c}\text { ALT } \\
(\mathrm{cm})\end{array}$ & $\begin{array}{c}\text { PROD } \\
\mathrm{kg} \mathrm{ha}^{-1}\end{array}$ & $\begin{array}{c}\text { MMA } \\
(\mathrm{g})\end{array}$ & $\begin{array}{c}\text { TO } \\
(\%)\end{array}$ & $\begin{array}{c}\text { RO } \\
\mathrm{kg} \mathrm{ha}^{-1}\end{array}$ \\
\hline Genótipos & 12 & $8,32^{\text {** }}$ & $46,0^{\text {** }}$ & $5,68^{\text {** }}$ & $15,62^{\text {** }}$ & $4,71^{\text {** }}$ & $3,84^{\text {n* }}$ & $10,74^{\text {** }}$ & $11,19^{\text {** }}$ \\
Bloco & 3 & $4,27^{* *}$ & $1,00^{\text {ns }}$ & $2,65^{\text {ns }}$ & $1,74^{\text {ns }}$ & $1,41^{\text {ns }}$ & $2,10^{\text {ns }}$ & $0,25^{\text {ns }}$ & $0,82^{\text {ns }}$ \\
Erro & 36 & -- & -- & -- & -- & -- & -- & -- & -- \\
\hline Média & -- & 45,6 & 61,3 & 18,9 & 147,3 & 4046,9 & 78,7 & 23,1 & 961,6 \\
CV & -- & 21,6 & 1,8 & 7,7 & 5,3 & 20,7 & 8,2 & 9,9 & 19,0 \\
\hline
\end{tabular}

** e ns, correspondem a significativo a $5 \%$ de probabilidade pelo teste $\mathrm{F}$ e não significativo, respectivamente.

$\mathrm{Na}$ Tabela 2 verifica-se que os maiores stands de plantas foram observados nos genótipos BRS G39, M734(T), BRS G37, BRS G30, BRS G35, BRS G40, BRS G38, BRS G34 e BRS G36 que não se diferenciaram pelo teste de Scott-Knott. Os menores stands foram observados nos genótipos BRS G41, BRS G42, EMBRAPA 122 e MG 341. Levando-se em consideração que todas as sementes foram submetidas às mesmas condições para germinarem, supõe-se que o maior stand esteja relacionado com uma maior taxa de germinação, e esta por sua vez, tem relação direta com a qualidade fisiológica da semente. Embora o genótipo BRS G39 tenha apresentado maior stand de plantas, o mesmo mostrou-se ser mais susceptível a oídio, o que pode ter influenciado o desempenho em outras variáveis.

O florescimento inicial (DFI) ocorreu entre 57 e 67 dias após a semeadura, sendo a média de 61,30 dias (Tabela 2). Os genótipos BRS G34, BRS G37, BRS G38, BRS G39, BRS G40, BRS G42 e Embrapa 122 foram os mais precoces. Segundo a classificação apresentada por ROSSI (1998), podem ser considerados de ciclo precoce as variedades e híbridos cujo período desde a emergência até o florescimento é de 55 a 65 dias, e de ciclo médio os materiais cujo este período compreenda entre 65 a 70 dias. Sendo assim os genótipos BRS G36 e MG341 seriam classificados como de ciclo médio.

TABELA 2: Teste de médias entre os diferentes genótipos para as variáveis stand de plantas (STD), data de floração inicial (DFI), diâmetro de capítulo (DC) e altura de plantas (ALT).

\begin{tabular}{ccccc}
\hline GENÓTIPO & $\begin{array}{c}\text { STD } \\
\text { (plantas })\end{array}$ & $\begin{array}{c}\text { DFI } \\
(\text { dias })\end{array}$ & $\begin{array}{c}\text { DC } \\
(\mathrm{mm})\end{array}$ & $\begin{array}{c}\text { ALT } \\
(\mathrm{cm})\end{array}$ \\
\hline BRS G30 & $55,50 \mathrm{a}$ & $62,50 \mathrm{c}$ & $190,8 \mathrm{~b}$ & $162,18 \mathrm{~b}$ \\
BRS G34 & $49,00 \mathrm{a}$ & $58,50 \mathrm{~d}$ & $186,5 \mathrm{~b}$ & $135,90 \mathrm{~d}$ \\
BRS G35 & $51,25 \mathrm{a}$ & $65,00 \mathrm{~b}$ & $183,3 \mathrm{~b}$ & $144,90 \mathrm{c}$ \\
BRS G36 & $42,00 \mathrm{a}$ & $66,75 \mathrm{a}$ & $184,5 \mathrm{~b}$ & $179,00 \mathrm{a}$ \\
BRS G37 & $56,00 \mathrm{a}$ & $57,75 \mathrm{~d}$ & $181,5 \mathrm{~b}$ & $139,45 \mathrm{c}$ \\
BRS G38 & $50,00 \mathrm{a}$ & $58,50 \mathrm{~d}$ & $188,8 \mathrm{~b}$ & $139,50 \mathrm{c}$ \\
BRS G39 & $70,75 \mathrm{a}$ & $57,75 \mathrm{~d}$ & $158,5 \mathrm{c}$ & $141,20 \mathrm{c}$ \\
BRS G40 & $50,75 \mathrm{a}$ & $58,25 \mathrm{~d}$ & $183,8 \mathrm{~b}$ & $134,23 \mathrm{~d}$ \\
BRS G41 & $20,75 \mathrm{~b}$ & $62,25 \mathrm{c}$ & $225,0 \mathrm{a}$ & $151,48 \mathrm{c}$ \\
BRS G42 & $26,75 \mathrm{~b}$ & $59,00 \mathrm{~d}$ & $195,5 \mathrm{~b}$ & $126,20 \mathrm{~d}$ \\
EMBRAPA 122 & $32,25 \mathrm{~b}$ & $58,00 \mathrm{~d}$ & $193,8 \mathrm{~b}$ & $134,15 \mathrm{~d}$ \\
M734 (T) & $56,50 \mathrm{a}$ & $65,00 \mathrm{~b}$ & $169,2 \mathrm{c}$ & $163,00 \mathrm{~b}$ \\
MG 341 & $31,00 \mathrm{~b}$ & $67,00 \mathrm{a}$ & $217,0 \mathrm{a}$ & $163,25 \mathrm{~b}$ \\
\hline
\end{tabular}


A precocidade no florescimento é uma característica interessante quando o genótipo também apresenta uma maturação fisiológica mais rápida. Isto favorece a antecipação da colheita evitando perdas por incidência da chuva levando a germinação da semente, por ataque de pássaros ou de pragas de final de ciclo. Resultados semelhantes foram observados por ANDRADE et al. (2011) e BALBINOT JR. et al. (2009), que também indicaram o genótipo Embrapa 122 como precoce ao avaliarem o desempenho de diferentes genótipos de girassol.

O diâmetro médio do capítulo nos genótipos avaliados foi de $189 \mathrm{~mm}$, sendo o maior $(217 \mathrm{~mm})$ e menor (158,5 mm) valor observado nos genótipos MG 341 e BRS G39, respectivamente. De acordo com MELO et al. (2006), cultivares comerciais de girassol produzem capítulos com diâmetro variando entre 129 e 200 $\mathrm{mm}$, aproximando-se dos valores observados neste estudo. Os genótipos de menor diâmetro, corroboraram com CAPONE et al. (2012), que obtiveram valores semelhantes onde o diâmetro médio do capítulo foi de $161 \mathrm{~mm}$, estudando diferentes cultivares de girassol e épocas de semeadura.

Com relação a altura de plantas verificou-se que o genótipo BRS G36 foi o mais alto com $179 \mathrm{~cm}$ diferindo dos demais, e os genótipos de menor estatura foram BRS G42, BRS G40, BRS G34 e Embrapa 122 pelo teste de médias. Resultados semelhantes foram observados por CADORIN et al. (2012) ao avaliarem diferentes épocas de semeadura entre genótipos de girassol na variação da altura de plantas. SANTOS \& GRANJEIRO (2013) avaliando o desempenho de cultivares de girassol em Campina Grande também encontraram diferenças na altura de plantas e atribuem esta variação a capacidade genética de crescimento de cada material.

A produtividade de grãos variou de $2589,50 \mathrm{~kg} \mathrm{ha}^{-1}$ (mínimo) a $5803,00 \mathrm{~kg}$ ha ${ }^{1}$ (máximo). Os genótipos MG 341 e BRS G41 se comportaram como sendo os mais produtivos. Os melhores resultados podem estar relacionados, a capacidade genética na adaptação às condições locais de solo e clima. A produtividade média de grãos foi de $4046,9 \mathrm{~kg} \mathrm{ha}^{-1}$, valor este $153 \%$ superior a média nacional divulgada pela CONAB para safra 2013/14 que é $1597 \mathrm{~kg} \mathrm{ha}^{-1}$. Deve-se levar em consideração que a produtividade média nacional em sua maioria é representada por lavouras cultivadas sem o uso de irrigação. GOMES et al. (2012) obtiveram produtividade variando entre 4788 e $6963 \mathrm{~kg} \mathrm{ha}^{-1}$, em experimento com diferentes lâminas de irrigação suplementar com microaspersão.

TABELA 3.Teste de médias entre os diferentes genótipos para as variáveis produtividade (PROD), massa de mil aquênios (PMA), teor de óleo (TO) e rendimento de óleo (RO).

\begin{tabular}{ccccc}
\hline GENÓTIPO & $\begin{array}{c}\text { REND } \\
\left(\mathrm{kg} \mathrm{ha}^{-1}\right)\end{array}$ & $\begin{array}{c}\text { MMA } \\
(\mathrm{g})\end{array}$ & $\begin{array}{c}\text { TO } \\
(\%)\end{array}$ & $\begin{array}{c}\text { RO } \\
\left(\mathrm{kg} \mathrm{ha}^{-1}\right)\end{array}$ \\
\hline BRS G30 & $3951,2 \mathrm{~b}$ & $79,91 \mathrm{a}$ & $22,03 \mathrm{c}$ & $862,85 \mathrm{c}$ \\
BRS G34 & $3374,3 \mathrm{~b}$ & $72,58 \mathrm{~b}$ & $26,19 \mathrm{~b}$ & $879,75 \mathrm{c}$ \\
BRS G35 & $3456,4 \mathrm{~b}$ & $66,44 \mathrm{~b}$ & $25,17 \mathrm{~b}$ & $870,12 \mathrm{c}$ \\
BRS G36 & $4049,5 \mathrm{~b}$ & $86,68 \mathrm{a}$ & $19,95 \mathrm{c}$ & $807,71 \mathrm{c}$ \\
BRS G37 & $4018,8 \mathrm{~b}$ & $78,25 \mathrm{a}$ & $24,58 \mathrm{~b}$ & $979,47 \mathrm{c}$ \\
BRS G38 & $3131,2 \mathrm{~b}$ & $75,48 \mathrm{~b}$ & $28,79 \mathrm{a}$ & $891,00 \mathrm{c}$ \\
BRS G39 & $2589,5 \mathrm{~b}$ & $69,06 \mathrm{~b}$ & $22,97 \mathrm{c}$ & $593,69 \mathrm{~d}$ \\
BRS G40 & $4015,1 \mathrm{~b}$ & $85,48 \mathrm{a}$ & $24,70 \mathrm{~b}$ & $985,09 \mathrm{c}$ \\
BRS G41 & $5731,0 \mathrm{a}$ & $81,27 \mathrm{a}$ & $30,44 \mathrm{a}$ & $1747,06 \mathrm{a}$ \\
BRS G42 & $4432,5 \mathrm{~b}$ & $81,93 \mathrm{a}$ & $25,40 \mathrm{~b}$ & $1121,73 \mathrm{c}$ \\
EMBRAPA 122 & $4231,6 \mathrm{~b}$ & $81,31 \mathrm{a}$ & $20,59 \mathrm{c}$ & $862,39 \mathrm{c}$ \\
M734 (T) & $3826,1 \mathrm{~b}$ & $78,52 \mathrm{a}$ & $15,59 \mathrm{~d}$ & $576,20 \mathrm{~d}$ \\
MG 341 & $5803,0 \mathrm{a}$ & $86,35 \mathrm{a}$ & $23,19 \mathrm{c}$ & $1324,59 \mathrm{~b}$ \\
\hline
\end{tabular}

Médias seguidas pela mesma letra na coluna não diferem entre si pelo teste de Scott-Knott $(p<0,05)$. 
Segundo CASTRO \& FARIAS (2005), quando a cultura do girassol é submetida a restrições hídricas prolongadas, normalmente ocorre diferença de massa entre as sementes. Essa afirmação é contrária aos resultados obtidos neste experimento, onde observou-se que mesmo sem restrição hídrica a massa de mil aquênios variou de 66,44 g (BRS G35) a 86,68 g (BRS G36), havendo portanto diferença entre os genótipos cultivados sob o mesmo regime hídrico. RIBEIRO et al. (2011) relatam que a medida que aumenta a massa de mil aquênios há uma redução do teor de óleo.

Houve grande variação entre os genótipos para o teor de óleo nos aquênios como pode ser observado na Tabela 3. O menor e o maior teor de óleo observado foi de $15,59 \%$ e $30,44 \%$, para os genótipos M734 e BRS G41, respectivamente, sendo o teor médio observado de 23,81\%. Diversos autores relatam que o teor de óleo varia entre 30\% e 45\% (GOMES et al., 2011; NUNES et al., 2013). Contudo, deve-se levar em conta que neste estudo a extração de óleo foi por prensagem, o que resulta num rendimento inferior ao da extração pelo método de Soxleht que utiliza solventes. OLIVEIRA \& VIEIRA (2004) relatam ter conseguido teor de óleo variando entre $9,6 \%$ e $20,3 \%$ com extração em miniprensa.

O menor e maior rendimento de óleo obtido foi de 593,69 e 1747,06 kg ha-1, para os genótipos BRS G41 e BRS G39 (Tabela 3), respectivamente, sendo a média para este parâmetro $961,64 \mathrm{~kg} \mathrm{ha}^{-1}$. Em comparação com os resultados obtidos por RIBEIRO et al. (2011) verifica-se que 38\% dos genótipos estudados seriam classificados como sendo de alto rendimento de óleo.

Observa-se na Tabela 4, que o rendimento de óleo (RO) apresentou uma correlação positiva $(r=0,83)$ com a produtividade de grãos (PROD). Outra variável que também se correlacionou positivamente com a produtividade de grãos foi o diâmetro do capítulo (DC) que apresentou um coeficiente de correlação $r=0,84$. Resultados semelhantes também foram observados por GOMES et al. (2012), que verificaram correlação positiva $(r=0,73)$ entre a produtividade de grãos e o diâmetro do capítulo.

TABELA 4. Análise de correlação entre variáveis morfológicas e de produção entre os genótipos de girassol avaliados.

\begin{tabular}{ccccccc}
\hline & DFI & ALT & DC & PROD & MMA & RO \\
\hline STD & $-0,169$ & 0,035 & $-\mathbf{0 , 8 2 8}$ & $-\mathbf{0 , 7 2 6}$ & $-\mathbf{0 , 6 2 7}$ & $\mathbf{- 0 , 6 7 3}$ \\
DFI & & $\mathbf{0 , 7 8 1}$ & 0,200 & 0,313 & 0,218 & 0,105 \\
ALT & & & 0,104 & 0,227 & 0,276 & $-0,012$ \\
DC & & & & $\mathbf{0 , 8 4 1}$ & $\mathbf{0 , 5 9 4}$ & $\mathbf{0 , 8 2 7}$ \\
PROD & & & & & $\mathbf{0 , 6 6 0}$ & $\mathbf{0 , 8 3 0}$ \\
PMA & & & & & & 0,404 \\
\hline
\end{tabular}

$\mathrm{DFI}=$ floração inicial após a semeadura; $\mathrm{ALT}=$ altura de plantas; $\mathrm{DC}=$ diâmetro do capítulo; $\mathrm{PROD}=$ produtividade de grãos; $\mathrm{UMI}=$ umidade dos grãos; $M M A=$ peso de mil aquênios; $\mathrm{RO}=$ rendimento de óleo.

$\mathrm{Na}$ Figura 2, observa-se que o diâmetro do capítulo correlacionou-se negativamente com o stand de plantas e positivamente com a produtividade de grãos. Desta forma, maior stand de plantas resultam em menor diâmetro do capítulo, enquanto que, capítulos de maior diâmetro resultam em maior produtividade de grãos. Segundo ALKIO et al. (2003), capítulos de tamanho maior tendem a ter maior proporção de aquênios grandes e mais pesados, e esse por sua vez têm mais tempo para o enchimento. Concordando com estes autores, observou-se neste estudo essa 
correlação positiva $(r=0,594)$ entre as variáveis diâmetro de capítulo e massa de mil aquênios (Tabela 4).
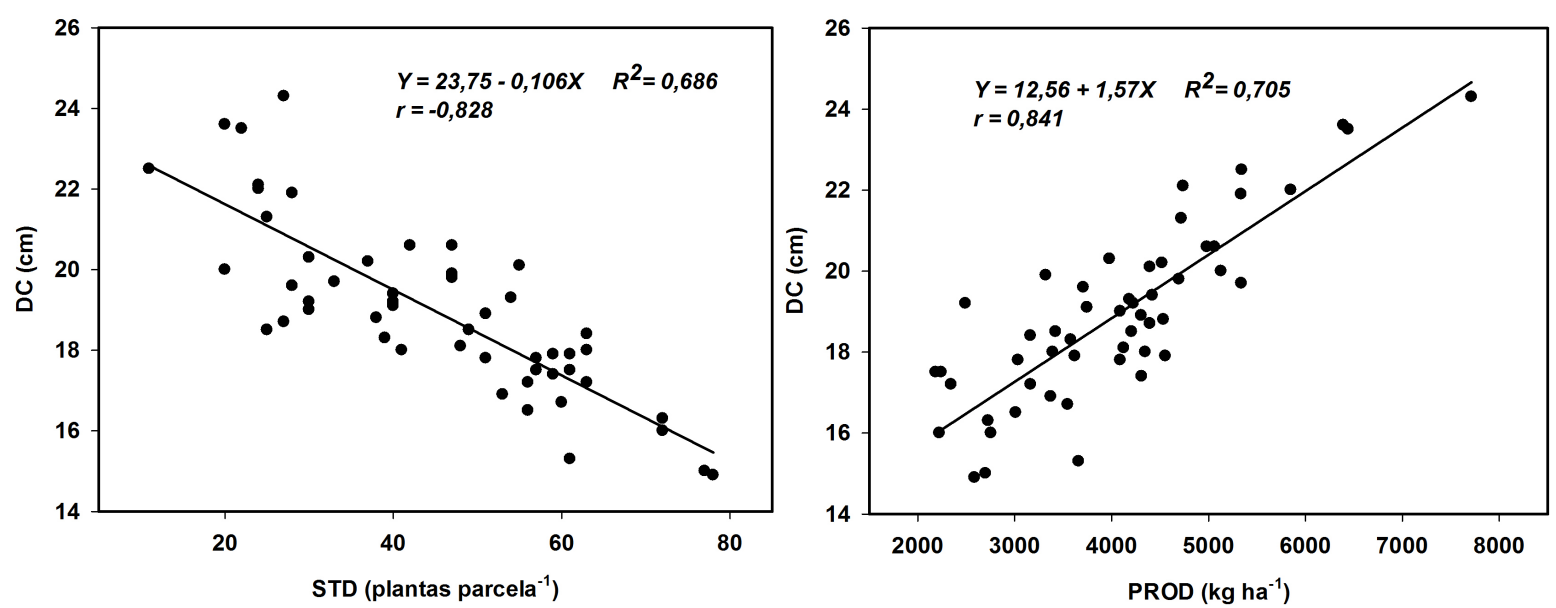

FIGURA 2. Correlação entre o diâmetro do capítulo (DC) e as variáveis stand de plantas (STD) e produtividade de grãos (PROD).

O rendimento de óleo demonstrou correlação positiva com as variáveis produtividade de grãos $(r=0,827)$ e diâmetro do capítulo $(r=0,827)$, de maneira que o aumento em uma destas variáveis promove incremento no rendimento de óleo nos genótipos avaliados (Figura 3).
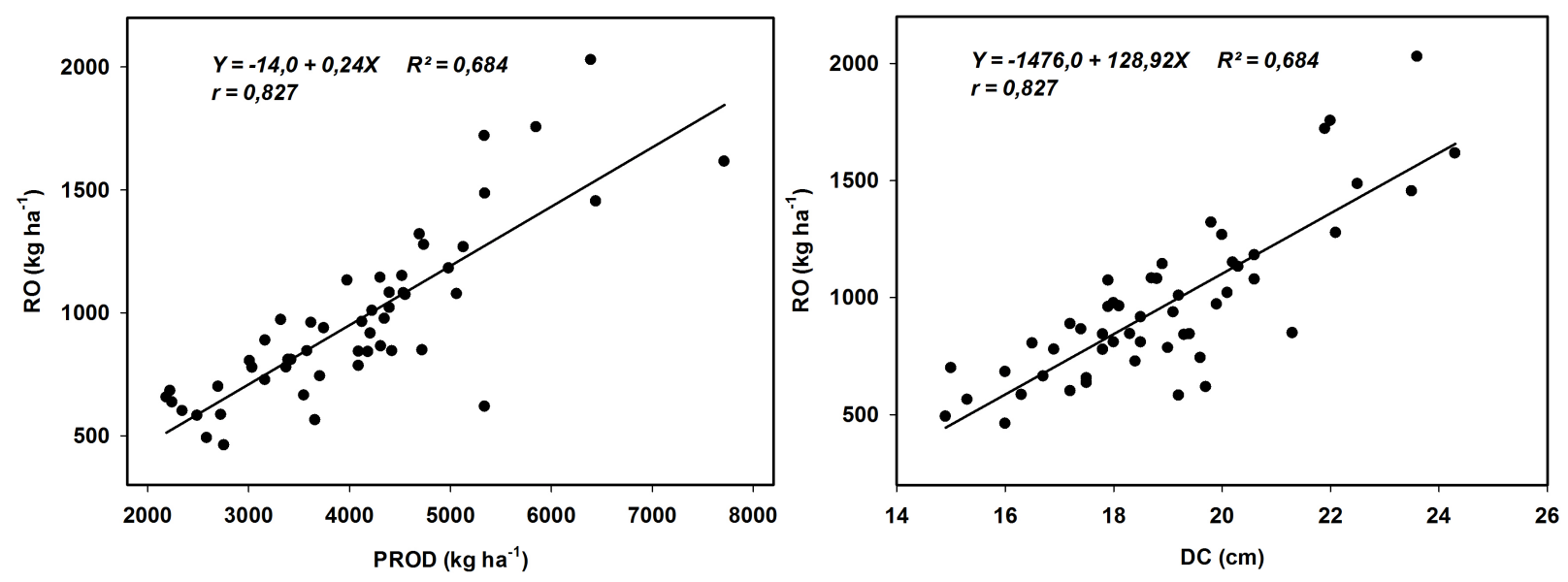

FIGURA 3. Correlação entre o rendimento de óleo $(\mathrm{RO})$ e as variáveis produtividade de grãos (PROD) e diâmetro do capítulo (DC).

\section{CONCLUSÕES}

A produtividade média dos genótipos avaliados é superior a média nacional. grãos.

Os genótipos BRS G41 e o MG341 apresentaram a maior produtividade de

O genótipo BRS G41 apresenta o maior teor e rendimento de óleo. 


\section{REFERÊNCIAS}

ALKIO, M.; SCHUBERT, A.; DIEPENBROCK, W.; GRIMM, E. Effect of source-sink ratio on seed set and filling in sunflower (Helianthus annuus L.). Plant, Cell and Environment, v.26, n.10, p.1609-1619, 2003.

ANDRADE, W. C.; ROLIM, G. G.; COÊLHO, A. A.; ALVARENGA, C. F. S.; SANTOS, L. G. Desempenho de diferentes cultivares de girassol no perímetro irrigado de São Gonçalo, município de Sousa-PB. Enciclopédia Biosfera, v.7, n.12, p.1-6, 2011.

BALBINOT JUNIOR, A. A.; BACKES, R. L.; SOUZA, A. M. Desempenho de cultivares de girassol em três épocas de semeadura no Planalto Norte Catarinense. Scientia Agraria, v.10, n.02, p.127-133, 2009.

BRASIL. Ministério da Agricultura, Pecuária e Abastecimento. Regras para Análise de Sementes. Brasília: MAPA/ACS, 2009. 399p.

CADORIN, A. M. R.; SOUZA, V.Q.; MANFRON, P.A.; CARON, B.O.; MEDEIROS, S.L.P. Características de plantas de girassol, em função da época de semeadura, na Região Noroeste do Rio Grande do Sul. Ciência Rural, v.42, n.10, p.1738-1743, 2012.

CAPONE, A.; SANTOS, E. R.; FERRAZ, E. C.; SANTOS, A. F.; OLIVEIRA, J. L.; BARROS, H. B. Desempenho agronômico de cultivares de girassol no sul do estado do Tocantins. Journal of Biotechnology and Biodiversity, v.3, n.3, p.13-23, 2012.

CASTRO, C.; FARIAS, J. R. B. Ecofisiologia do Girassol. In: LEITE, R.M.V.B.C.; BRIGHENTI, A.M.; CASTRO, C. (Ed.). Girassol no Brasil. Londrina: Embrapa Soja, 2005. 641p.

CAVASIN JÚNIOR, C. P. A cultura do girassol. Guaiba, Agropecuária, 2001. 69 p.

CONAB. (Companhia Nacional de Abastecimento). Acompanhamento de Safra Brasileira: Grãos. Levantamento, Novembro 2014. Disponível em < http://www.conab.gov.br/OlalaCMS/uploads/arquivos/14_09_10_14_35_09_boletim_ graos_setembro_2014.pdf> Acesso: 05 dezembro de 2014 >.

FREITAS, G.A. de. Análise Econômica da Cultura do Girassol no Nordeste. INFORME RURAL ETENE, Banco do Nordeste, 2012.

GAZZOLA, A.; FERREIRA JUNIOR, C.T.G.; CUNHA, D.A.; BORTOLINI, E.; PAIAO, G.D.; PRIMIANO, I.V.; PESTANA, J.; D'ANDRÉA, M.S.C.; OLIVEIRA, M.S. A Cultura do Girassol. ESALQ/USP, Piracicaba - SP, 2012. 69p.

GOMES, E. P.; FEDRI, G.; ÁVILA, M. R.; BISCARO, G. A.; REZENDE, R. K. S.; JORDAN, R. A. Produtividade de grãos, óleo e massa seca de girassol sob diferentes lâminas de irrigação suplementar. Revista Brasileira de Engenharia Agrícola e Ambiental, v.16, n.3, p.237-246, 2012. 
MELLO, R.; NÖRNBERG, J. L.; RESTLE, J.; NEUMANN. M.; QUEIROZ, A. C.; COSTA, P. B.; MAGALHÃES, A. L. R.; DAVID, D. B. Características fenológicas, produtivas e qualitativas de híbridos de girassol em diferentes épocas de semeadura para produção de silagem. Revista Brasileira de Zootecnia, v.35, p.672-682, 2006.

NUNES, B. T.; PILON, A.; FLUMINHAM, A. Avaliação do desempenho agronômico de genótipos de girassol (Helianthus annuus L.) cultivados na região oeste paulista e análise do rendimento de óleo, matéria seca e proteína bruta. IX Fórum Ambiental da Alta Paulista, v.9, n.1, p.150-165, 2013.

OLIVEIRA, M. F.; VIEIRA, O. V. Extração de óleo de girassol utilizando miniprensa. Londrina: Embrapa Soja (Documentos 237), 2004, 27p.

RIBEIRO, M. F. S.; DAROS, E.; CAIRES, E. F.; VASCONCELLOS, M. E. C. Desempenho agronômico da cultura do girassol em diferentes condições edafoclimáticas do Sudeste paranaense. Bragantia, v.70, n.3, p.550-560, 2011.

ROSSI, R. O. Girassol. Curitiba: TecnoAgro, 1998. 333 p.

SANTOS, J. F.; GRANJEIRO, J. I. T. Desempenho de cultivares de girassol na microrregião de Campina Grande, PB. Tecnologia \& Ciência Agropecuária, v.7, n.2, p.41-47, 2013.

OLIVEIRA, I. R.; CARVALHO, H. W. L.; CARVALHO, C. G. P.; LIRA, M. A.; FERREIRA, F. M. B.; TABOSA, J. N.; MACEDO, J. J. G.; FEITOSA, L. F.; RODRIGUES, C .S.; MELO, K. E. O.; MENEZES, A. F.; SANTOS, M. L. Avaliação de cultivares de girassol em municípios dos Estados da Bahia, Alagoas, Sergipe e Rio Grande do Norte: ensaios realizados no ano agrícola de 2008. Comunicado técnico (documento 105). Aracajú, SE. 2010.

TORDIN, C. Importância do girassol como alimento, fonte de energia e recuperação do solo. Embrapa Meio Ambiente, 2008. Disponível em: <http://www.cnpma.embrapa.br> . Acesso em: 28 de fevereiro de 2013. 